\title{
USO DE FERRAMENTAS GENÉTICAS NA IDENTIFICAÇÃO DAS COMUNIDADES BACTERIANAS DE QUEIJOS ARTESANAIS: UMA REVISÃO SISTEMÁTICA DA LITERATURA ${ }^{1}$
}

\author{
Letícia Aparecida Cruvinel ${ }^{2}$ \\ Saulo Nascimento de Melo $^{3}$ \\ Gustavo Augusto Lacorte ${ }^{4}$
}

\begin{abstract}
RESUMO
Queijos artesanais constituem naturalmente um rico microbioma, cujas interações são de extrema importância para a formação dos produtos, contribuindo para o sabor e a textura desses alimentos. Até a década de 1980, a classificação e a identificação de bactérias se baseavam em comparações fenotípicas. A partir dos anos 2000, com a consolidação do uso das técnicas de biologia molecular, tornou-se possível a caracterização de qualquer comunidade bacteriana presente numa amostra. Neste contexto, o presente trabalho visa demonstrar a importância do uso de técnicas moleculares na identificação de microrganismos presentes em queijos artesanais, como forma de melhorar a eficiência dessa identificação. Com o presente estudo, podemos concluir que técnicas moleculares são de grande eficiência na detecção de microrganismos presentes em queijos artesanais e, na grande maioria das vezes, essas técnicas detectam grupos de microrganismos com maior rapidez e precisão quando comparadas com técnicas tradicionais. Outro fator relevante é o fato de essas novas técnicas permitirem a identificação de microrganismos que não seriam identificados em técnicas tradicionais dependentes de cultivo.
\end{abstract}

Palavras-chave: Biologia Molecular, Queijos Artesanais, Revisão Sistemática.

\section{INTRODUÇÃO}

\footnotetext{
${ }^{1}$ Como citar este artigo:

CRUVINEL, L. A.; MELO, S N.; LACORTE, G. A. Uso de ferramentas genéticas na identificação das comunidades bacterianas de queijos artesanais: uma revisão sistemática da literatura. ForScience: revista científica do IFMG, Formiga, v. 5, n. 2, e00310, out. 2017. Edição especial.

2 Mestranda em Sustentabilidade e Tecnologia Ambiental pelo Instituto Federal de Educação, Ciência e Tecnologia de Minas Gerais (IFMG) - Campus Bambuí. Currículo Lattes: http://lattes.cnpq.br/6691733142289368. E-mail: leticiacruvinel29@gmail.com.

3 Graduado em Ciências Biológicas pelo IFMG - Campus Bambuí. E-mail: saulomelobio@hotmail.com. Currículo Lattes: http://lattes.cnpq.br/2227481540925142.

${ }^{4}$ Pós-doutorado em Parasitologia pela Universidade Federal de Minas Gerais (UFMG). Doutorado e mestrado em Genética pela UFMG. Atualmente é coordenador e docente do Programa de Pós-Graduação em Sustentabilidade e Tecnologia Ambiental do IFMG - Campus Bambuí. E-mail: gustavo.lacorte@ifmg.edu.br: Currículo Lattes: http://lattes.cnpq.br/8111751949796851.
}

ForSci.: r. cient. IFMG, Formiga, v. 5, n. 2, e00310, out. 2017. Edição especial. 
A fabricação artesanal de queijos no estado de Minas Gerais tem como principal característica a utilização do leite cru, de forma que a microbiota presente no leite torna-se parte fundamental no processo de produção conferindo as características sensoriais típicas deste produto (NOBREGA, 2007). Além do leite cru, a utilização de parte do soro residual do processo de produção - conhecido como "pingo" - como fermento endógeno, insere no processo de produção uma microbiota diversificada, representativa da região na qual o produto é fabricado, que direciona a fermentação e maturação do queijo conferindo características sensoriais peculiares (MARINO, 2003). Apesar do antigo conhecimento prático da importância da utilização do fermento endógeno no processo de produção de Queijos Minas Artesanais, pouco se sabe a respeito da sua composição, além do fato de que ele é formado por uma complexa associação microbiana de comunidades de bactérias do ácido lático (BAL) e comunidades de leveduras (PARENTE, 1997).

É sabido que queijos artesanais possuem naturalmente uma flora bacteriana, sendo a interação desses microrganismos de extrema importância na formação de produtos artesanais (KONGO et al, 2007; MARTÍN-PLATERO, 2008), uma vez que são em grande parte responsáveis pelo sabor e textura desse alimento (SILVA, 2012).

Até a década de 1980 a classificação e identificação de bactérias, se baseavam em comparações fenotípicas, incluindo características morfológicas, fisiológicas, metabólicas e químicas das células. Entretanto, a partir dos anos 2000, com a consolidação do uso das técnicas de sequenciamento em larga escala do gene de RNA ribossômico 16S (rRNA), como marcador molecular de caracterização de grupos bacterianos, tornou-se possível a caracterização de qualquer comunidade bacteriana presente numa amostra de qualquer material - água, solo, alimentos, efluentes - fornecendo informações consideráveis sobre a composição e o papel desempenhado por estas comunidades que participam tanto do processo de produção de alimentos quanto aquelas que são consideradas contaminantes, sem a necessidade de isolamento e cultivo (RAPPÉ; GIOVANNONI, 2003; TRINGE; HUGENHOLTZ, 2008). Dessa forma, a caracterização de comunidades bacterianas na indústria de alimentos passou de uma tarefa extremamente árdua na década de 80 para uma tarefa relativamente simples na década atual (ERCOLINI, 2013).

Considerando o contexto, já se sabe que existem variações nas características sensoriais (aparência, consistência, aroma e sabor) de queijos artesanais entre os produtores de uma mesma região o que influencia diretamente no valor agregado do produto final. Como as comunidades bacterianas intrínsecas ao processo de produção contribuem para a 
CRUVINEL L. A.; MELO, S. N.; LACORTE, G. A. Uso de ferramentas genéticas na identificação das comunidades bacterianas de queijos artesanais: uma revisão sistemática da literatura

determinação destas características sensoriais, o presente trabalho visa demonstrar a importância do uso de técnicas moleculares na identificação de microrganismos presentes em queijos artesanais, como forma de melhorar a eficiência dessa identificação. A partir daí, futuramente podem ser desenvolvidas formas de seleção/separação de microrganismos benéficos e contaminantes, visando o desenvolvimento de produtos de controle, bem como maximizar a eficiência do processo de maturação de queijos artesanais. As informações levantadas neste trabalho serão úteis para o desenvolvimento de trabalhos similares aplicados à problemática da produção do Queijo Minas Artesanal da Serra da Canastra.

\section{DESENVOLVIMENTO}

\subsection{Metodologia}

Em linhas gerais, para atingir o objetivo principal deste trabalho que é reunir em um único documento, as principais informações disponíveis na literatura sobre o uso de ferramentas de caracterização das comunidades bacterianas em queijos artesanais produzidos no Brasil, foi empregada a metodologia de revisão sistemática de dados da literatura.

Para seleção das publicações, primariamente foram feitas buscas nas plataformas de buscas mais utilizadas pelo meio acadêmico brasileiro: (1) a plataforma de busca do Periódicos CAPES, desenvolvida pelo órgão governamental brasileiro CAPES; (2) a plataforma Google Acadêmico, desenvolvida pela empresa americana Google e de acesso livre; (3) a plataforma PubMed desenvolvida pelo Instituto Nacional de Saúde dos Estados Unidos (National Institute of Health - NIH) e, também, de acesso livre; e (4) a plataforma Web of Science, desenvolvida pela empresa canadense Thomson Reuters e de acesso restrito a assinantes. Entretanto, foi observada uma elevada sobreposição de estudos, com isso a busca foi limitada a duas plataformas: a Periódicos CAPES e Google Acadêmico. As plataformas PubMed e Web of Science foram descartadas pelo fato de apresentar abrangência mais limitada que as demais e acesso limitado, respectivamente.

As buscas foram realizadas nos idiomas inglês e português, estruturadas em quatro etapas (Figura 1). A primeira etapa envolveu a avaliação dos resultados apresentados pela ferramenta de busca das plataformas selecionadas, após buscas com palavras-chave relacionadas ao tema central do trabalho. A partir destas listas de publicações geradas, seguiuse a segunda etapa que consistiu na de triagem inicial de publicações não relacionadas ao 
tema central do trabalho, listadas por viés da ferramenta de busca. Essa triagem foi realizada por meio da leitura do título de cada publicação listada. A terceira etapa envolveu a triagem de publicações efetivamente relacionadas ao tema central do trabalho, por meio da leitura e avaliação de resumo e conclusão de cada trabalho resultante da triagem realizada na etapa 2. Por fim, as publicações selecionadas na etapa 3 foram utilizadas como fonte de informação para a realização da discussão sobre o tema do trabalho.

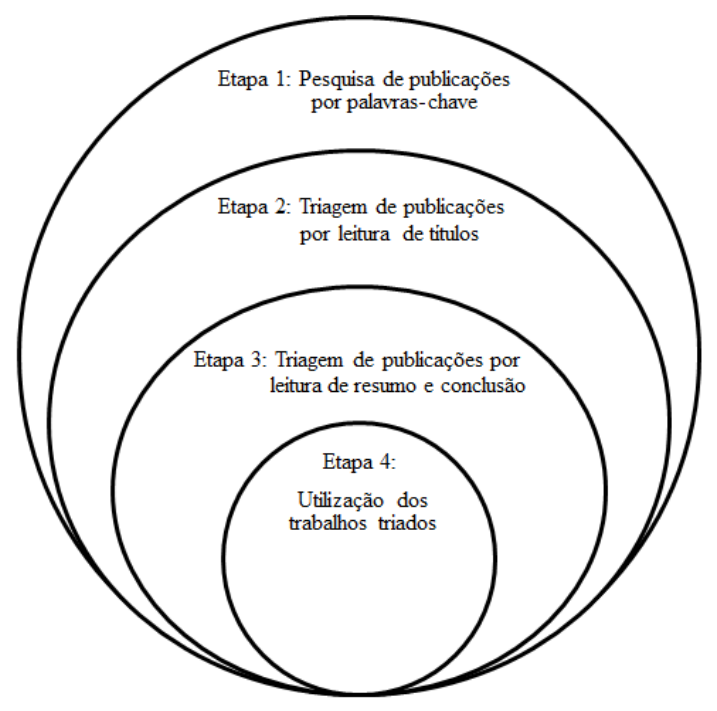

Figura 1 - Representação esquemática dos passos metodológicos seguidos na revisão sistemática Fonte: Autor.

\subsection{Resultados e discussão}

Os trabalhos foram selecionados usando um critério livre de seleção, porém sempre optando por artigos com metodologia eficiente e desenvolvidos usando amostras de queijos artesanais provindos de regiões tradicionais.

Os trabalhos selecionados para análise foram:

a) A1- "Avaliação da microbiota bacteriana do queijo de coalho artesanal produzido na região Agreste do estado de Pernambuco", autoria de Silva et al. (2012).

b) A2- "Avaliação da qualidade microbiológica do queijo-de-minas artesanal do SerroMG”, autoria de Blant, Fonseca e Silva (2007).

c) A3- "Microbiologia de queijo tipo Minas Frescal produzido artesanalmente", autoria de Loguercio e Aleixo (2001). 
CRUVINEL L. A.; MELO, S. N.; LACORTE, G. A. Uso de ferramentas genéticas na identificação das comunidades bacterianas de queijos artesanais: uma revisão sistemática da literatura

d) T1- "Comparação de métodos para pesquisa de Salmonella sp. e Listeria sp. e avaliação microbiana e físico- química em queijo minas artesanal", autoria de Mata (2009).

e) T2- "Caracterização bioquímica e genética de bactérias lácticas isoladas de queijo serrano", autoria de Almeida (2007).

f) T3- "Identificação de espécies de Enterococcus isoladas de Queijo Minas tipo frescal através da análise do polimorfismo dos Fragmentos de restrição de parte do gene 16s rRNA Amplificado pela PCR", autoria de Scheidegger (2009).

Os objetivos e metodologias dos trabalhos selecionados e discutidos estão representados na tabela a seguir.

Tabela 1 - Trabalhos selecionados e seus respectivos objetivos e metodologias

\begin{tabular}{|c|c|c|}
\hline Artigos & Objetivos & Metodologias utilizadas \\
\hline A1 & $\begin{array}{l}\text { Analisar a microbiota bacteriana do queijo de } \\
\text { coalho artesanal da região Agreste de } \\
\text { Pernambuco, quanto à qualidade } \\
\text { microbiológica e ao perfil ácido-láctico. }\end{array}$ & $\begin{array}{l}\text { Reação em cadeia da polimerase } \\
\text { (PCR) e amplificação de regiões } \\
\text { específicas por meio de primer espécie } \\
\text { específicos. }\end{array}$ \\
\hline A2 & $\begin{array}{l}\text { Avaliar a qualidade microbiológica do queijo- } \\
\text { de- minas artesanal do Serro e observar a } \\
\text { variação da microbiota do queijo recém- } \\
\text { fabricado e no último dia do prazo de validade }\end{array}$ & Técnicas tradicionais de identificação. \\
\hline A3 & $\begin{array}{l}\text { Avaliar a qualidade higiênico-sanitária do } \\
\text { queijo Minas Frescal produzido artesanalmente } \\
\text { e comercializado em Cuiabá, através da } \\
\text { investigação da carga de microrganismos } \\
\text { indicadores em amostras coletadas em dois } \\
\text { pontos de comercialização. }\end{array}$ & Técnicas \\
\hline $\mathrm{T} 1$ & $\begin{array}{l}\text { Comparar o método convencional de detecção } \\
\text { de Salmonella sp., Listeria monocytogenes e } \\
\text { Listeria sp. com métodos rápidos para análise } \\
\text { de queijo Minas artesanal e verificar a } \\
\text { sobrevivência de Listeria innocua à maturação }\end{array}$ & $\begin{array}{l}\text { Técnicas tradicionais de identificação, } \\
\text { VIDAS- LMO e métodos moleculares } \\
\text { - PCR. }\end{array}$ \\
\hline $\mathrm{T} 2$ & $\begin{array}{l}\text { Classificar isolados de bactérias lácticas } \\
\text { predominantes em queijos Serranos comerciais } \\
\text { através de métodos bioquímicos e analises } \\
\text { morfológicas, bem como caracterizá-los } \\
\text { através do uso de métodos moleculares } \\
\text { baseados em PCR: RAPD, ISSR, BOX, REP, } \\
\text { ERIC e TAP. }\end{array}$ & $\begin{array}{l}\text { Técnicas tradicionais de identificação } \\
\text { e métodos moleculares baseados em } \\
\text { PCR: RAPD, ISSR, BOX, REP, ERIC } \\
\text { e TAP. }\end{array}$ \\
\hline $\mathrm{T} 3$ & $\begin{array}{l}\text { Implantar a técnica da PCR/RFLP com as } \\
\text { enzimas DdeI, HaeIII e HinfI associada a } \\
\text { alguns testes bioquímicos para uma } \\
\text { identificação de Enterococcus spp. isolados de } \\
\text { amostras de queijo Minas tipo frescal. }\end{array}$ & $\begin{array}{l}\text { PCR/RFLP tendo como base o gene } \\
16 \text { do rDNA, algumas técnicas } \\
\text { bioquímicas. }\end{array}$ \\
\hline
\end{tabular}

Fonte: Almeida (2007); Blant, Fonseca e Silva (2007); Loguercio e Aleixo (2001); Mata (2009); Scheidegger (2009); Silva et al. (2012). 
CRUVINEL L. A.; MELO, S. N.; LACORTE, G. A. Uso de ferramentas genéticas na identificação das comunidades bacterianas de queijos artesanais: uma revisão sistemática da literatura

Os resultados do artigo A1 mostraram a eficiência da técnica molecular na identificação de contaminantes do queijo coalho artesanal produzido na região Agreste do estado de Pernambuco, visto que todos os gêneros e espécies testados foram encontrados. Os alvos dos primers foram: Enterococcus, Enterococcus faecium, Enterococcus faecalis, Streptococcus thermophilus, Lactococcus lactis, Lactococcus raffinolactis e Lactobacillus casei (SILVA et al. 2012).

Já o artigo A2, avaliando a presença de Staphylococcus coagulase positiva, Salmonella spp. e Listeria monocytogenes por meio de técnicas tradicionais de identificação, demonstrou que $92,5 \%$ das amostras analisadas estavam fora do padrão, sendo que 82,5\% apresentaram contagens de Staphylococcus coagulase positiva acima de $10^{3} \mathrm{UFC} /$ grama. Nenhuma amostra de queijo apresentou contaminação por Salmonella spp ou Listeria monocytogenes. A média logarítmica do número de Staphylococcus coagulase positiva para os queijos recémfabricados se mostrou mais alta que a média para os queijos estocados a $10^{\circ} \mathrm{C}$, mas como citado pelo próprio autor é importante ressaltar que as toxinas uma vez produzidas são resistentes às condições de estocagem apresentadas no trabalho (BLANT; FONSECA; SILVA, 2007).

Os autores Blant, Fonseca e Silva (2007) - A2 - não identificaram Salmonella sp. e Listeria monocytogenes em seu trabalho. Entretanto, no trabalho de Mata (2009) o método convencional também não foi eficiente na detecção de Salmonella sp em um total de 63 unidades amostrais, enquanto o método imunoenzimático VIDAS - SLM detectou o mesmo contaminante em 3,17\% das amostras. Este autor classificou essas amostras como falsos positivos, em decorrência de possíveis reações cruzadas ocasionadas pela especificidade do anticorpo com outros antígenos correlacionados ou mesmo possíveis contaminações. $\mathrm{O}$ método convencional a PCR- BAX também não detectou Salmonella sp em nenhuma amostra.

O trabalho A3, de autoria de Loguercio e Aleixo (2001) usando técnicas tradicionais de identificação, demonstraram que na determinação de coliformes fecais, 28 amostras $(93,33 \%)$ apresentaram-se fora dos padrões legais exigidos para queijo Minas Frescal. Na contagem de Staphylococcus aureus, em 29 amostras (96,67\%) obtiveram-se valores superiores a $10^{3} \mathrm{ufc} / \mathrm{g}$, e apenas uma amostra (3,33\%) estava em conformidade com o padrão legal. Nesse trabalho o autor propõe avaliar a qualidade higiênico-sanitária do queijo Minas Frescal por meio da investigação da carga de microrganismos indicadores, entretanto, o 
trabalho só deu destaque a dois tipos de contaminantes, coliformes e $S$. aureus, que não podem ser usados como representantes da microbiota total do produto.

O trabalho de Mata (2009) - T1- compara técnicas tradicionais de identificação de microrganismos com técnicas alternativas (imunoanálise e reação da polimerase em cadeiaPCR) em amostras de Queijo Minas Artesanal. Com os resultados a autora pôde observar que os métodos convencionais e moleculares demonstraram resultados semelhantes na identificação de Salmonella sp., bem como VIDAS - LMO (imunoanálise) para $L$. monocytogenes, porém os testes usando PCR não foram feitos com outros contaminantes. A autora também apresentou uma tabela adaptada do trabalho de Boer e Beumer (1999) demonstrando a eficiência do uso da PCR quando comparado às outras técnicas, sendo possível vizualizar que além do tempo gasto ser significantemente menor que o gasto em técnicas convencionais (12hrs contra 4-6 dias), o limite de detecção é também muito mais eficaz, sendo que em técnicas convencionais o limite de detecção é de $1 \mathrm{UFC} / \mathrm{mL}$ em $25 \mathrm{~g}$ e $10^{3}$ para PCR.

No trabalho de Almeida (2007) - T2- , os marcadores TAP-PCR demonstraram alta correlação com a classificação bioquímica, sendo que os marcadores RAPD, BOX e REPPCR apresentaram elevada capacidade discriminatória em Lactobacillus e coeficientes de similaridade com elevada correlação com aqueles calculados a partir de marcadores TAPPCR, o que não ocorreu com os dados de ISSR.

A tese de Scheidegger (2009) -T3- demostrou que a técnica de PCR/RFLP mostrou-se simples, eficiente e rápida para identificação das espécies de Enterococcus em Queijo Minas tipo frescal, usando o primer para região conservada do gene 16S rRNA e endonucleases de restrição (deI, HaeIII e HinfI). A autora usou também testes bioquímicos com intuito de reforçar os resultados. Primeiramente, foram usadas as duas técnicas em isolados bacterianos da coleção laboratorial, porém a técnica molecular foi capaz de identificar $100 \%$ das amostras. No entanto algumas provas bioquímicas não coincidiram com a literatura disponível, dificultando a interpretação dos resultados, não sendo possível a identificação de algumas espécies. Quando as duas técnicas foram aplicadas em isolados do QMA, ambas foram capazes de realizar a identificação, entretanto a técnica bioquímica demostrou alguns perfis atípicos entre as amostras.

Métodos convencionais de detecção de microrganismos, além de uma demanda maior de tempo, podem sofrer com interferência de fatores ambientais e possíveis variações na expressão gênica dos microrganismos, o que pode afetar o poder discriminatório dos testes 
CRUVINEL L. A.; MELO, S. N.; LACORTE, G. A. Uso de ferramentas genéticas na identificação das comunidades bacterianas de queijos artesanais: uma revisão sistemática da literatura

bioquímicos. Outra dificuldade são as células viáveis não cultiváveis, que não são detectadas nessa metodologia (FARBER, 2001; MARIN; LEMOS; FREITAS, 2006).

De qualquer forma], por mais eficiente que sejam as técnicas moleculares é necessário um estudo prévio de qual metodologia usar, bem como qual o marcador ideal para o grupo em questão. No trabalho de Almeida (2007) o marcador ISSR não foi considerado eficiente, uma vez que, embora tenha demonstrado elevada capacidade de discriminação, o mesmo chegou a separar isolados considerados como idênticos por outros marcadores, o que já poderia ser esperado, uma vez que marcador possui um elevado grau de polimorfismo, não sendo o marcador ideal para microrganismos, uma vez que possuem elevada taxa de mutações e recombinação genética, favorecendo o uso de marcadores específicos para regiões mais conservadas do DNA.

\section{CONCLUSÃO}

Com o presente estudo podemos concluir que técnicas moleculares são de grande eficiência na detecção de microrganismos presentes em queijos artesanais. Na grande maioria das vezes essas técnicas detectam com uma maior facilidade e rapidez microrganismos quando comparadas com técnicas tradicionais. Outro fator relevante é o fato de que essas novas técnicas permitirem a identificação de microrganismos que não seriam identificados em técnicas tradicionais, por não terem uma biologia conhecida, crescimento lento ou mesmo não serem cultiváveis.

\section{REFERÊNCIAS}

ALMEIDA, R. C. de. Caracterização bioquímica e genética de bactérias lácticas isoladas de queijo serrano. 2007. 68 f. Dissertação (Mestrado em Biotecnologia) - Universidade de Caxias do Sul, Caxias do Sul. 2007.

BOER, E.; BEUMER, R.R. Methodology for detection and typing of foodbome microrganisms. Internatinal Jornal of food microbiology, v. 50, n. 1, p. 119-130, 1999.

BRANT, L. M.; FONSECA, L. M.; SILVA, M. C. Avaliação da qualidade microbiológica do queijo-de-minas artesanal do Serro-MG. Arq. bras. med. vet. Zootec, v. 59, n. 6, p. 15701574, 2007. 
CRUVINEL L. A.; MELO, S. N.; LACORTE, G. A. Uso de ferramentas genéticas na identificação das comunidades bacterianas de queijos artesanais: uma revisão sistemática da literatura

ERCOLINI, D. High-throughput sequencing and metagenomics: Moving forward in the culture-independent analysis of food microbial ecology. Applied and Environmental Microbiology. v. 79, n. 10, p. 3148-3155, 2013.

FARBER, J. M. et al. Molecular typing and differentiation. In: DOWNES, F. P (Ed.). Compendium of methods for the microbiological examination of foods. 4. ed. Washington: American Public Health Association, 2001. p. 127-156.

KONGO, J. M. et al. Characterization of dominant lactic acid bacteria isolated from São Jorge cheese, using biochemical and ribotyping methods. Journal of applied microbiology, v. 103, n. 5, p. 1838-1844, 2007.

LOGUERCIO, A. P.; ALEIXO, J. A. G. Microbiologia de queijo tipo Minas Frescal produzido artesanalmente. Cienc. Rural, v. 31, n. 6, 2001.

MATA, G. M. S. C. Comparação de métodos para pesquisa de Salmonella sp. e Listeria sp. e avaliação microbiana e físico-química em queijo Minas artesanal. 2009. 109 f. Dissertação (Mestrado em Microbiologia Agrícola) - Universidade Federal de Viçosa, 2009.

MARIN, V. A.; LEMOS, A. A. de; FREITAS, E. I. de. Detecção de patógenos presentes nos alimentos: a falta de padronização e validação de métodos moleculares no Brasil. Hig. aliment, v. 20, n. 145, p. 46-49, 2006.

MARINO, M.; MAIFRENI, M.; RONDININI, G. Microbiological characterization of artisanal Montasio cheese: analysis of its indigenous lactic acid bacteria. FEMS

Mocrobiologicy Letters, v. 229, n. 1, p. 133-140, 2003.

MARTIN-PLATERO, A. M.; VALDIVIA, E.; MAQUEDA, M.; MARTIN-SANCHEZ, I.; MARTINEZ-BUENO M. Polyphasic approach to bacterial dynamics during the ripening of Spanish farmhouse cheese, using culturedependent and -independent methods. Appl Environ Microbiol. v. 74, n. 18, p. 5662-5673, 2008.

NÓBREGA, J. E. da. Caracterização do fermento endógeno utilizado na fabricação do queijo Canastra no município de Medeiros, Minas Gerais, com ênfase em leveduras. 2007. 94 f. Dissertação (Mestrado em Ciência e Tecnologia de Alimentos) - Universidade Federal de Viçosa, 2007.

PARENTE, E.; ROTA, M.; RICCIARDI, A.; CLEMENTI, F. Characterization of natural inicializadora cultures used in the manufacture of Pasta Filata cheese in Basilicata (Southern Italy). International Dairy Journal. v. 7, n. 12, p. 775-783, 1997.

RAPPE, M. S.; GIOVANNONI, S. J. The uncultured microbial majority. Annu Rev Microbiol v. 57, p. 369-394, 2003. 
CRUVINEL L. A.; MELO, S. N.; LACORTE, G. A. Uso de ferramentas genéticas na identificação das comunidades bacterianas de queijos artesanais: uma revisão sistemática da literatura

SCHEIDEGGER, E. M. D. Identificação de espécies de enterococcus isoladas de queijo minas tipo frescal através da análise do polimorfismo dos fragmentos de restrição de parte do gene 16S rRNA amplificado pela PCR. 2009. 83 f. Dissertação (Mestrado em Vigilância Sanitária) - Instituto Nacional de Controle de Qualidade em Saúde, Fundação Oswaldo Cruz, Rio de Janeiro, 2009.

SILVA, R. A. et al. Avaliação da microbiota bacteriana do queijo de coalho artesanal produzido na região Agreste do estado de Pernambuco. Arq. bras. med. vet. zootec, v. 64, n. 6, p. 1732-1738, 2012.

TRINGE, S. G.; HUGENHOLTZ, P. A renaissance for the pioneering 16S rRNA gene. Current opinion in microbiology, v. 11, n. 5, p. 442-446, 2008.

\title{
USE OF GENETIC TOOLS IN THE IDENTIFICATION OF BACTERIAL COMMUNITIES OF ARTISAN CHEESES: A SYSTEMATIC REVIEW OF LITERATURE
}

\begin{abstract}
Artisanal cheese are naturally rich microbiome whose microbial interactions are crucial to conformation of these artisanal food products contributing to the flavor and texture. Until the 80 's , bacterial classification and identification were based on phenotipic approaches and from the 2000's, with consolidation of molecular techniques, it has become possible a refined classification of whole bacterial communities accessed from any type of sample. In this context, our primary goal is to depict the importance of recent molecular techniques of bacterial applied to artisanal cheese microbiomes, as a way of improve the characterization of their communities. Here we highlighted the efficiency and robustness of these approaches and, in most cases, they have characterized the microbial diversity faster and more refined than by conventional methods. Furthermore, molecular approaches allow identifications that would not be possible through conventional culture-dependent approaches.
\end{abstract}

Keywords: Molecular Biology. Artisanal cheese. Systematic review.

Submetido em: 24/06/2016

Aprovado em: 15/07/2016

Publicado em: 06/10/2017 